\title{
Making the drone strange: the politics, aesthetics and surrealism of levitation
}

\author{
Peter Adey \\ Royal Holloway University of London, Surrey, TW20 0EX, UK \\ Correspondence to: Peter Adey (peter.adey@rhul.ac.uk)
}

Received: 19 February 2016 - Revised: 11 August 2016 - Accepted: 19 August 2016 - Published: 18 November 2016

\begin{abstract}
In this paper I decentre the drone from a different kind of vertical figure that has its own prehistory and parallel history of being aloft and particular sets of aesthetic geographies we might productively deploy to reorder what we think about drones, and especially the human's place in or outside of them. The paper explores in what ways we might examine the drone from other points of view that are technical and political, but also theological, magical, artistic and aesthetic. The prehistoric or parallel aerial figure to be considered is the levitator, the subject or thing that floats without any attributable mechanical force, visible or physical energy source. The paper draws on notions of aesthetics and politics in order for the levitator not to be compared with the drone, but to enable its very different visual and aesthetic regimes to begin to redistribute quite a different set of drone geographies that are ambiguous, mystical, gendered and sexed.
\end{abstract}

\section{Introduction}

In a published piece in Cabinet Mark Dorrian (2014) reminds us that drones, especially militarized ones, have been received and anticipated by other and earlier aerial figures. He compares the prowess of the drone to the blind seer, who embodies "the idea of a powerful, far-reaching, and penetrating vision $[\ldots]$ its sentience exceeds or transcends the quotidian world of the senses" (2014:48). This is odd. In the drone we find not only the future of a barely imaginable if apparently cleaner and more precise violence that militaries and governments are keen to communicate, but analogues of mythic figures possessing powerful capacities of sight and war-making. These seemingly incompatible apprehensions often coincide. Dorrian finds that representations of "archaic monsters of vision" are used in order to advertise military efficacy. For others such as Jordan Crandall (2014), the drone is a "winged fusion of human beast and machine". History combines with myth and a monstrous biology in Adam Rothstein's (2015:xiv) view, where the drone is "a monster capable of terrible acts" as well as a "hero, uniting disparate technological forces" or even "a mythical creature not unlike a unicorn or a zombie".

In other words, there are other kinds of registers of the drone that we might attend to which have been folded into several of the drone narratives recent scholarship has interrogated. This is obvious within the not too subtle signifying economies of the military and the media, industries which pull on primal and archaic feelings of familiarity about the drone within surveillance and weapons systems such as the "Gorgon Stare" and ARGUS (Autonomous Real-Time Ground Ubiquitous Surveillance). Of course, whether such notions, imaginaries and affects of the drone are misplaced or misguided, or we find curious exaggerations in their analogies of omniscient vision from classical figures (Wall and Monahan, 2011), they are unquestionably there. As Noys has recently written, "our experience of the "reality" of drones involves these myths and metaphysics, which return to haunt us" (2015:4).

Therefore, there might be reason to retain the drone within a more ambiguous misty and mythic register because actually the mythic invocations do matter. They take us to a level of expression where drones are experienced and imagined. They express the sensations and experiences that might elude the ever-increasing attempts at fidelity to the drone's view.

It is not the intent of this paper to explore the drone from within its own modern history, to which authors have located earlier versions in the spaces of Vietnam, and even the Second World War and before (Gregory, 2011; Shaw, 2016), nei- 
ther do I want to position the drone within wider visual, cultural and political histories of the view from above and an emergent geography of the vertical (see Dorrian and Pousin, 2013; Adey et al., 2013; Graham and Hewitt, 2013). Instead, in this paper, I try to decentre the drone from a different kind of vertical figure that has its own prehistory and parallel history of being aloft and particular sets of aesthetic geographies we might productively redeploy (Hawkins and Straughn, 2015).

This is to take the drone from a side-long view, a kind of squint - if you will - in order that we might begin to reorder what we think about drones, and especially the human's place in or outside of them. What profit might there be, to which this paper devotes its argument, in exploring the drone from other points of view that are technical and political, but also theological, magical, artistic and aesthetic? The precursive or parallel aerial figure to be considered is the levitator, the subject or thing that floats without any attributable mechanical force or visible or physical energy source.

It is worth briefly spending time exploring the different traditions and contexts from which levitators have been born (Adey, 2017). The levitator could not be more different to the drone. Our ideas of levitators come from a wide range of traditions in philosophy, theology, politics, science and visual culture. Christian, and almost every other major faith's, narratives of ascension would follow the rising of the soul to join with God, commonly allegorized in pilgrimages, rituals and rites of passage up hills, steps and mountains and, ultimately, floating figures (Della Dora, 2014; see also Wylie, 2002). In pre-modern societies, animistic belief systems hold the shaman as levitator elect. Whilst our early modern and medieval political ideas of sovereignty and kingship, as expressed in illustrations or manifested in legal traditions, have placed rulers and kings somewhere between earth and the heavens (Kantorowicz, 1957). Just about levitating and floating kings, saints and holy figures were common in the middle ages.

From political-theological notions of sovereignty, it is unsurprising that levitators have been embodied in the more recent cultural expressions of hot and cold warring superpowers found within comic book heroes (see Dittmer, 2012, but especially Bukatman, 2003). The flight of figures such as Superman lays the platform for an omniscient and penetrating view to see across the city, and potentially through buildings. Sight becomes a weapon as a red laser beam, able to cut through any material. Superman's aboveness or detachment sets him apart from others. For Neal Curtis, levitation is thus a common trope for superheroes who are frequently represented as "hovering just above the ground when speaking to mere mortals or those differently abled" (Curtis, 2015:155). Superman and other superheroes regularly "speak down" to others.

The point here is not to attempt to make any rough or blunt comparisons between the drone and levitators, or to explore artistic interventions that are engaging drones in undoubtedly fascinating and important ways - the work of James Bridle, Joy Garnett and others has been borne in mind elsewhere. Rather, it is to show that levitators can help us make the drone strange, sometimes by helping us to find them more familiar. Indeed, as Jablonowski (2015) has written on amateur drone culture following John Law's writings from science studies (Law, 2002), decentring the drone may mean accounting for its "fractionality" as a multiple object. This means avoiding any "false juxtapositions" between different points of view, but recognizing that multiple perspectives, stories and narratives may make up the reality of an object.

Instead of instantiating the drone's newness or unique properties the paper contends that the making strange of the drone through alternative aerial figures can offer a modest kind of critique, specifically by drawing on the levitator to offer the potential space for an aesthetic analysis and subversion (for the wider import of a surreal and creative geography see Hawkins, 2013; Fenton, 2005; Pinder, 2013). The paper draws on notions of aesthetics and politics in order for the levitator not to be compared with the drone, but to enable its very different visual and aesthetic regimes to begin to redistribute quite a different set of drone geographies that are ambiguous, mystical and also highly gendered and sexed.

In the following section the paper sets up the levitator and the drone in relation to the omniscience usually assumed of aerial and vertical perspectives and technologies. In Sect. 3 the paper then sets up the framing for the paper's more substantive analysis of levitators and drones through surrealism and surrealists, and aesthetics in the work of Ranciere, before exploring three different registers of levitators and drones: the register of stories and testimony; magic and myth; and embodiment and abstraction.

\section{Departing omniscience}

To begin the paper will start to outline several sets of tendencies we could identify within levitators and the drone. These quickly begin to depart one another as the levitator diverges from the usual visual and aesthetic regimes we are used to associating with the drone and its wider networks.

Ideas of levitation surprisingly penetrate writings on sovereignty. "The sovereign rises above the body" writes Jean-Luc Nancy (2007), seeing that the sovereign does not just act from high places, an altar, a throne or a mountain. For Nancy, the sovereign is the summit, it is height. The sovereign is the most high or "inequivalent", and hence various authors have sought to capture its detachment as exceptional powers, most obviously in Agamben (1998, 2005). As Nancy explains, "Its name is superlative: literally what raises itself above from below, and what is no longer comparable or relative. It is no longer in relation, it is an absolutum" (Nancy, 2007:97). Affirming wider debates about the king's nature, the sovereign here escapes any earthly limitations on their powers such as by law, and does not even correspond to 
ideas of structure or hierarchy that would sustain or constrain them. Peter Gratton concludes that the sovereign may as well be self-supporting, an "ex nihilo", founding itself on nothing other than its own rapport to itself' (2012:205).

In many respects the drone has come to stand in for and perform particular aspects of this form of sovereign, fetishized and technological power (Shaw and Akhter, 2012). Drones are complicit within decisions over life at a distanceto kill - often by foreign powers extraterritorially. Conducted outside of legal war zones the drone has begun to remake the norms of sovereign power wherein exceptionality and exceptional conditions, such as "imminent threat", have helped provide the grounds for their deployment (see Kindervater, 2015).

Levitating figures such as sovereigns - in their worst possible incarnation discussed above - also help capture something of the literal and figurative exceptionality drones appear to embody through their apartness in the skies. This association with flight, vertical perspectives and omniscience - or omnipotence - others find are shared in the grandiose visions of modernist urban planning. Adnan Morshed (2004) has aligned superheroes, such as the pre- and post-war renderings of Superman, not with sovereign power, but architects and planners in the form of Le Corbusier's famous gestural hand (over Ville Contemporaine) and Norman Bel Geddes' futurama at the 1939 New York World's fair. Morshed calls this collision of vertical urban power an aesthetics of ascendance (see also Graham and Hewitt, 2013).

However, wider perspectives on levitation begin to tell us that the levitator does not typically occupy a position of omniscience so easily, and as we will see, drones might not either.

Not everyone levitates. The historian of religion Mircea Eliade (1964) would argue that levitation is fairly limited to "sovereigns, heroes, initiates", and we should add, superheroes, mystics, artists, fashion models, astronauts and cosmonauts bestowed with privileged knowledge or powers. However, levitators do not often or always occupy the position of the powerful.

Levitators have often been marginalized, castigated or objectified. They have been the subject of sartorial humour especially in Jewish representations, stories and literature of the luftmensch, a figure that derides and portrays the rootless and wandering Jew (see Berg, 2008, and Adey, 2013). European visions of the Orient frequently accounted for exoticized and eroticized women levitated by a male magician. Some of the first moving images from India were filmed by Thomas Edison in 1902 in a film titled Hindoo Fakir, showing a woman levitated by a magician before being transformed into a butterfly. As Italo Calvino (1988) has suggested, this trend for lightness or levity may well be a response to the "precarious existence" of potential levitators, expressed perhaps in racism, a form of sexual exploitation or poverty. Levitation is not always wilful either. Levitators are not that ready to leave the ground as divine ecstatics and their witnesses tes- tify. Their bodies succumb neither to gravity or the oneiric impulse to float away (Bachelard, 1988). Many levitators find themselves held in suspension by others, sometimes tentatively for a while, and at other times, unwittingly.

There are curious but quite different circuits of travel here. In the last 50 years we have seen deployments of the drone in the colonial spaces of South Asia and eventually Iraq and Afghanistan. The drone's historical antecedents can of course be found in colonial air policing in almost the same spaces of the Middle East (Satia, 2014; Neocleous, 2013). However, whereas the far off would be determined as the proving grounds of both the drone and the levitator, it is the levitator that tends to become the subject of colonial and highly gendered formations of power. The drone tends to be understood as wielding it uninterrupted.

\section{Surrealism and the sensible: critique and imagining other worlds}

By turning to the different myths that abut the levitator, articulated through a variety of different kinds of modes of address, from scientific exploration of the paranormal, to artistic forms of expression and resistance, we might reflect back on the drone from really very different aerial points of view. The levitator is in many respects diametrically opposed to the drone. It is almost non-technological. The levitator is given lift from spiritual, magical or unexplainable motive force, as well as deceit. It is passive and rarely violent or, rather, it experiences violence against itself, and it rarely sees but is seen and objectified, if not exploited.

We could consider these alternative figures as providing us with different sets of aesthetic orders. As Ranciere (2006) has elaborated on the relationship between the political and sensible or aesthetic experiences, various orders partition or distribute the sensible so as to produce a common sense (see for instance Dikeç, 2012, 2013). The political and aesthetic collide when aesthetics enables the disruption of that order; when the distribution of the sensible becomes contested is a political moment. Crucially, for Ranciere and following Marshall (2013), aesthetics offers up openings or ruptures for the imagination of new kinds of futures, new worlds, "new ways of seeing and doing" (Marshall, 2013:57).

It is not that the levitator could or should offer us any kind of form of comparable aerial figure; in fact its complexity and historical specificity would make this task very difficult. Instead, the drone gathers together particular aesthetic orders, which naturalize certain political relations and make them invisible. By bringing the levitator's different aesthetic regimes to a juncture with the drone, we might begin to reveal those orders and invisibilities, and start to challenge them more consistently. For these specific modes of aesthetic address we might turn towards levitative engagements within surrealist artistic and political traditions in search of escape, critique and the imagining of other worlds. 
This aesthetic and political potential is actually common to the levitator. Remembering Calvino (1988), the levitator is an obvious figure of escapism. Through the exclusion of Jews in modern Europe, floating figures of the luftmensch in Marc Chagall and others both reinforced and railed against this persecution. In shamanism, the practical woes and precarity of "tribal life" through "drought, sickness, evil influences" could be transcended by spiritual and practical levitation. Indeed, within the socialist avant-garde - with which Chagall was closely related - weightlessness became a cosmic utopian ideal of emancipation within art, science fiction and architecture (Stites, 1989). In this sense levitation is a very real gesture of escape, an emancipation through just a little flight. As Calvino (1988) sees it, the body is shorn of weight, and, by "flying to another world, another level of perception", the levitator finds "the strength to change the face of reality".

We might then see the levitator as a directly radical figure. Scott Bukatman (2003), exploring Fat Boy Slim's music video "Weapon of Choice", directed by Spike Jonze in 2001, depicts Christopher Walken as an alienated business type, impassive in the foyer of a hotel. Along with the music, the video accelerates to animate what Bukatman describes as a "bricolage of sampled tracks, acts of fantastic mobility, and perceptual surprise (with the merest touch of shock)" (2003:2), as Walken dances, performs acrobatics and eventually flies in the lobby of a generic Los Angeles hotel. For Bukatman, the video offers a Certeaudian form of tactics, "of inhabitation and trespassing, a fantasy of repossessing both one's space and one's body, almost a jumping out of one's skin" (2003:2). The potential of Walken's mobility is what Bukatman describes as a remapping of the subject through weightless escape that transgresses social, spatial and bodily norms.

Within the longer trajectory of surrealist thought and practice, the relationship with levity is not uncomplicated but a troubled one. It is most problematic in the reduction of the female body to a levitated muse. Even one of the most highprofile proponents of surrealism, Salvador Dali, was happy to suspend partially unclad women on a photographic plate, or graphically dismembered on canvas limb by limb (see Sweeny-Risko, 2015, for a complication of this view). Dali and others also explored levity through bizarre and strange compositions in a bricolage of genre, style and myth. Dali's many encounters with levity, religion and science, would be expressed in his works of "nuclear mysticism", "mastering gravity" through what he called a "quantum realism" that would see artistic production as a form of atomic experimentation. Coexisting with his turn to science, however, was conflation of genres, belief systems and ontologies through a "mysticism" that he would declare, "is not only religious but also nuclear and hallucinogenic". Therefore, from photography to his paintings, Dali's works on levitation display mash-ups of Renaissance figures with magnifications of atomic shapes and spiritual iconography. "Mine St Teresa of
Avilia!" Dali cries, calling out the influential saintly levitator and mystic.

However, we may also come across the expression of levitation in surrealists who explicitly rejected motions of acquiescence or submission in their explorations of levitation, femininity and violence, such as the Spanish artist Remedios Varo (1908-1963). Varo fled with other women artists (such as Leonora Carrington), first from Spain and then from Nazioccupied Paris to take refuge in post-revolutionary Mexico during the Second World War. Her flight was completed with the aid of the Emergency Rescue Committee who would help other artists, writers and activist refugees to leave Europe. Varo's escape followed an inspiring but suffocating relationship with the poet Benjamin Peret, close friend of the Surrealist leader Andre Breton.

Like Carrington, Varo's works on levity can be seen as a form of supra-realism, turning to a variety of belief systems, folklore and alchemy, as well as experimental science. Freud, Jung and the famous theosophist and theorist of levitation, Madame Blavatsky, were authors among Varo's collection of books. Indeed, levitation is common to many female surrealists, Carrington famously devoting her convent school days to rebellion and eventual expulsion through efforts to levitate her body. In Varo's many numbered works we see solid bodies becoming light, their weight almost evaporating to the point that things tend to be shorn of their mass. Her imagery is chock full of ethereal floatings, "levitations, flights, ascents and heights" (Gonzalez, 2008:90) of things, cobblestones, instruments, floorboards, domestic spaces and other objects that rise and remain there, imbued with magical force. Levitation also reflected Varo's interest in science as well as spirituality. Varo's The Phenomenon of Weightlessness, depicting an Einstein-like scientist floating an earth-shaped globe orbited by a moon, would even be used as the front cover of a textbook on general relativity, The Riddle of Gravitation (Bergmann, 1968).

If we turn to Varo's work Banqueros en accion (1962), Varo reflects on the figure of the banker. A woman in a shawl watches them cautiously as three bankers float, cloaked and ominously above a city, reflecting Varo's anti-capitalist feelings, despite her courting commercial work in Venezuela. While this is perhaps one of the most ominous of Varo's works, Capillary Locomotion (1960) is easily the most enigmatic. Three men levitate in a corridor, or at least they appear to be levitating, until one recognizes that they are in-fact floating on their long beards that brush the floor below them, curling up as if a monkey tail. The men, whose hair on their heads appears vaporous and cloud-like, ride their beards as if bicycles, their moustaches held just like handlebars. Above them from a window, another man peers out and ensnares a women who is lifted by his beard. Her hands reveal the asymmetry of power with the men. Her's remain desperately outstretched, palm downwards, fingers reaching to hang on to her autonomy. The men hold their own in a grip. 
If surrealism offers sometimes quite subtle, and, at other times, not so delicate subversions of gendered and capitalist relations through the levitator, might the surrealists offer some critical potential in their shocks, combinations, inversions and animations to redistribute the sensible in Ranciere's terms? Therefore, holding together these qualities of the sensible and the surreal apprehensions of levitation, what kind of light might they help shed on the drone? I suggest that we can turn to three dominant aesthetic registers: stories and testimony; magic and myth; and embodiment and sexuality.

\subsection{Stories and narratives}

Levitators have always required audiences and testimony about them. Unlike the visual prowess of other vertical technological vehicles such as drones, the levitator can rarely see, neither does it readily archive its activities. The levitator requires that they are seen. The proof of the miracle of levitation in the eyes of the Catholic Church required empirical evidence from multiple and trusted sources. In the 17 th century, Saint Joseph - the so-called flying friar - was famously subjected to Prospero Limbertini's reforms of the Church's procedures in confirming holiness, and in testing the provenance of miraculous claims. These rested on the material evidence provided by witnesses, whilst the assessment of miracles rested in a juridical decision by the church's court (Vidal, 2007).

Therefore, alongside juridical claims to prove levitation had actually happened are numerous sets of truth claims, and different valuations of evidence and testimony. Unsurprisingly, expertise in the form of paranormal investigators, parapsychologists and the employment of weighing machines was common in investigations of levitators. Arthur Koestler would play an important role developing both a weighing machine and notions of levity. Koestler even tested his ideas by trying to levitate George Orwell - in perhaps the perfect juncture of levity, technology and the father of our notions of surveillance and control - at a dinner party (Scammell, 2011), before the Birkbeck physicist JB Hasted inherited the idea and possibly the inspiration for a levitation weighing machine, now held by the Science Museum in London. Other investigations would seek to measure and capture levitators through photography (see for instance Hiller, 2009). However, these forms of evaluation based on testimony do not fall into the singular goal of proving whether something had happened. The adjudicators on Saint Joseph were far more concerned over the cause of his levitation and whether his flights were magically or spiritually inspired. Indeed, many scientists and sceptical investigators of the paranormal, including well-known philosophers, were willing to believe that different mediums held a range of levitative powers. The power of narrative, or one's own phenomenal experience, overrode their commitments to scientific rationality and physical laws.

Drones are involved in very different kinds of witnessing, recording and evaluation to this. Most drone-deploying mil- itaries do in fact archive the communications and decisions of drone pilots, several of which have been released - albeit redacted - or leaked to the public to enable forms of journalist insight and legal redress. However, despite or perhaps because of these efforts the drone is still quite a misty object, refracted through a variety of narrative plays, knowledge and testimony, as well as shadows and hearsay, and convoluted pathways of data and communication.

Thought of in this way, what these testimonies may actually produce is vagueness and uncertainty. Rothstein and others highlight the drone's ambiguity as an object and the difficulty of revealing the assemblages into which it is made and caught. Recently Derek Gregory has demonstrated the confusions arising from the complexities of the chains of decisionmaking and targeting that drones perform in complex networks. For Gregory (2011) and others, such a visual and decisional shroud is the paradoxical resolution of wider societal and militaristic scopic regimes that have sought to make the battlefield more transparent, and the population anatomized. As combat, in other words, is made hypervisible, it also creates absences, blurrings and blind spots. Levitators should therefore help us insist, as Gregory (see 2011, and 2015) has begun to show, that the drone may play a part within complex targeting networks wherein the mists of confusion might quite often descend. Precisely because of the dispersed and distributed nature of drone violence, networked warfare may actually obfuscate rather than clarify a vision of conflict, warning us to be careful not to over-determine claims of drone legibility, the tightening of accuracy or the efficiency of kill chains either.

In other words, the partition of the sensible through drones and levitators seems to emphasize certain kinds of privileged knowledge, resting on the assumption that the drone can be made yet more visible, that bit more clear. Enormous efforts are conducted to "myth-bust" the drone (including the US Federal Aviation Authority, FAA, 2014) to determine what it can do, where it has been used and with what effect. Not only do these perspectives potentially obscure the multiple narratives and perspectives through which drones exist, and over which their governance struggles to perform, but they potentially reproduce the technological fetish of the all-seeing drone they have sought to question. Might levitators position us at different epistemological and aesthetic prisms through which the drone has been known, shown and proved, and cause us to resist ever-increasing attempts at fidelity?

Ian Shaw's (2015) recent review of Chamayou's (2015) Theory of a Drone suggests that Chamayou could be accused of a mythologizing of the drone by effacing the many networks of information, decision and law into which the drone is enrolled, and that Gregory and others have unveiled. However, while Chamayou overlooks the detailed relations into which the drone is assembled and performs, in their place he situates the drone into the context of Greek and Nordic narratives of invulnerability. Instead of simply effacing things, or losing the position of the drone within the webs of relations 
within which it is caught, what we could call Chamayou's mythic rendering of the drone performs a different kind of locating, more at home with the levitator. These help us to frame the drone into moral and ethical problems: should the drone's prosecution be virtuous or cause injustice? In what ways does its invisibility promote abuse? How might these mythologies of ancient storytelling compete with the contemporary myths of "precision", "surgical strikes" and "targeted killings"? In this manner, the mythological might also provide some kind of promise to draw the drone outside of the techno-political registers in which it is normally framed, but to more familiar ethico-moral register of stories where they can be familiarized and, thus, potentially understood, deliberated and criticized.

\subsection{Magic and mysticism}

Levitation is often marked by a fervour of a religious ceremony or exorcism, the apparatus of the séance (the 1967 peace march on the Pentagon to levitate and therefore exorcize it) and the techniques to enlighten or investigate these spaces and their accoutrements. Such techniques of making levitation, and making levitation known, help distribute the field of the sensible, as well as passions, excitement and other collective affects to both convince or reveal.

Let us first, however, explore relations of agency. The levitator is often understood as a spiritual vessel, a body submitted to another's distant will. Like other levitators, these apprehensions of levity do not celebrate the wilful omniscient view. The levitator does not hold the possessive gaze of ownership, surveillance or control as the drone may do by presencing its "pilot's" agency, but is more likely to be possessed in such a way that the subject is pushed out.

The lives of many Catholic saints, recorded by the Bollandists, stand out for the ways in which their flying ecstasies were accounted for and represented as miraculous. These accounts are almost certainly expressions of platonic and Christian mysticism, which hold how the soul could envelop a body in light and, with the levity of those rays, lift the body on high in ecstatic possession or transverberation. In the many writings of the 16th century Catholic mystic, Saint Teresa of Avilia, levity "comes as a quick and violent shock; you see and feel this cloud, [...] you are being carried away you know not where" (Warma, 1984). In this sense, the levitator is made exterior to their own body, and able to observe it.

Even if the drone obviously performs a completely different quality of violence to this - even if the drone is far from transcendent but regresses its targets through the shock of a missile into bare life - levitator and drone may converge here. The drone has tended to be constructed by those who wield it in such a way so as to reduce any sense of its autonomy (there have been numerous debates over the "autonomous" and "unmanned" in different drone acronyms) from human, and supposedly lawful and ethical, direction. Drones become positioned as mere vacant bodies or tools as opposed to intermediaries, as if to partition off a more lyrical, "agent-ful" and chancier kind of drone from common sense. (For a perspective on the non-human in warfare, see Forsyth, 2013, 2016.)

Within these registers, more overt critique and subversion might be possible. As we have seen, surrealism draws the levitator into different traditions of indigenous magic and spirit forces, bestowing material things with vital, animistic and non-human material agency that cultural geographers are beginning to show are so crucial to spaces of conflict (Forsyth, 2016; Thornton, 2015). This might alert us to the drone as a composite of agents, which may not always prove to be so reliable, and that may begin to help us reimagine quite what we mean by piloting and the control of the drone (on other unsettling distributions of agency in the context of aerial objects; see McCormack, 2017). What Crandall (2013) has called an object of both allure and threat, menace and desire, tends to obscure moments of drone failure, of malfunctioning communication systems, poorly manufactured or maintained parts, an "excessively flapping rudder". The official narrativization and bureaucratization tends to silence these flaws through illusion and creativity.

Surrealist bricolage may prove effective too. Combining different traditions and genres to approach the drone might not simply upset or invert several drone narratives, but once again bring the drone into the realm of an albeit strangely combined familiar. For instance, artist Philip Slagter uses a surrealist recomposition of an image of hummingbirds, an ambiguous character of Victorian levitative intrigue, which also features in many Mexico-Indian myths and stories. In Slagter, the future of drone wars may be microscopic in the form of mechanical swarming birds, based on a DARPA project on autonomous nano-drones. Slagter realizes this in DARPA, Hummingbirds and Poppies (2015): in one image, the drones fly aloft a pastoral scene of Teletubby-like children's characters frolicking below. In another, the mechanical drones are situated across a Middle Eastern backdrop with Apache-looking helicopters silhouetted against the desert sky.

Recent research is revealing of other kinds of dronemaking and the spaces of their exchange and circulation through elaborate but informal practices of representation and anticipation, designed in order to garner enthusiasm and excitement in the form of drone expos. For example, geographer Anna Jackman (2016) is beginning to reveal, as well as the economics of drones explored by other authors (Crampton et al., 2014), the buzz and atmosphere, the sociability, the speculative logics and the rhetoric of the spaces of drone circulation, consumption and exchange. From media reports to the spaces of the drone trade show and arms fairs, we learn that the drone economy is constituted by spaces of delight, enthusiasm and "circus"-like spectacle. These are affects that are seemingly incongruous to the drone's weighty politics, but permit its desire and exchange in what Rhys Machold has described as the spheres of security policy mobilities (2015). 
Art provides avenues for more direct aesthetic intervention into the sites of the drones' making (see Ingram, 2016, on the wider relations between art and geopolitics) too, especially through Dada-inspired satire. Infiltrating the spaces of other state-sponsored weaponry and drone trade shows, Jill Gibbon's various sketchbooks have given another perspective on the apparent informality of the drone and military arms industry. She characterizes not only the "fun" and excess discussed in relation to trade fairs, but also the politeness and hospitality where all is "light, clean and warm". Gibbon's self-declared window on the military-industrial complex, and notably the world's largest arms show, the Defence Security Exhibition International (DSEI), uses sketched drawings in order to peer beneath what she describes as the "veneer of civility" that veils one of the most obvious of moments when drones and the arms trade become visible. Gibbon describes a particularly evocative scene of weaponry and canapés.

Missiles glisten under spotlight [...] On every aisle there are plates of plums, grapes, nectarines, and chocolates. A string quintet plays Mozart on the back of a military truck. The arms trade is hiding in the light. (Gibbon, 2015:191).

\subsection{Bodies, gender, sexuality}

Finally, the levitator helps signal the highly gendered nature of other kinds of aerial bodies or subjects of levity. Whether real, fraudulent, imagined or inspired, women have been hooked away in the entanglement of beards, and lifted as the subject of a sexualized muse, the vehicle of another's will or ambition. The sexed and gendered submission to levitation is a projection of ideas that have aligned women with hysteria, perversion and sexual fantasies.

Teresa is notable in that she is one of the few levitators to have written widely and influentially about her encounters. Many flights were said to be done unconsciously, while Teresa's were a source of conscious embarrassment. Famously depicted in Bernini's St Teresa in Ecstasy, Teresa is portrayed lying on a cloud, a suspended erotic/ecstatic moment. Levitation in this form is a kind of affective exhaustion, a giving up or burning up of the subject and their passions, to be unburdened by depletion. Teresa's influential writings further emancipate her flights from anything to do with her own will. As she becomes ecstatic, she describes being pushed out and under the submission of another. However, just as her writings would be widely read, Teresa was also maligned by her many detractors as a delirious hysteric (Mazzoni, 1996). Pathologized in this way, her transverberation was regularly interpreted as a gendered symptom of hysteria or nymphomania.

If we move from Gibbon's attention to the spaces of drone consumption to the levitator's performance, we can bear in mind the context of late 19th and early 20th century female mediums. The most famous is probably Eusapia Palladino,

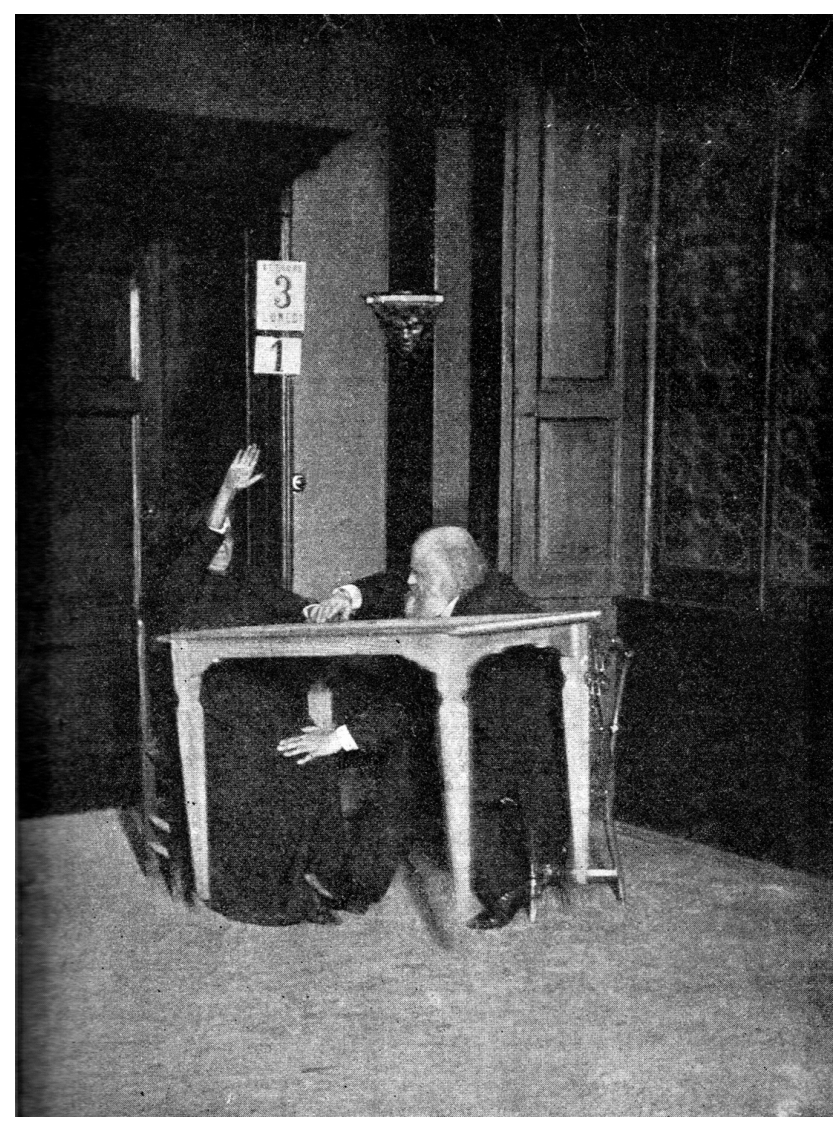

Figure 1. Palladino at the Milan sittings, 1892 (https://commons. wikimedia.org/wiki/File:Médium_et_Aksakof002.jpg)

whose levitations and séances (Fig. 1) would be exposed to the light of celebrity-following, as well as the sensitivities of scientific investigation. Palladino underwent experiments in Cambridge and Naples, as well as Paris, in front of witnesses such as Pierre and Marie Curie, Alfred Russel Wallace and the philosopher, Henry Sidgwick. Palladino, like many other female levitators, would be probably quite rightly accused of fraud, but as with Teresa, the taints on her abilities were commonly laced with the insinuation of sexual perversion. The darkness of the séance, and the intimate proximities of her body with others, alluded to a certain sexual frisson that bled into Palladino's maligned public image and apparently the scientific observers.

This intimacy might appear to be about as far away from the jocular masculinity the transcripts of drone pilots and sensors express in the darkened spaces of Creech Air Force Base, Nevada. However, the darkened and the aesthetic sexual insinuations of Palladino's séance setting may trigger our attention to what Jasbir Puar (2007:xii) has demanded in her reconnection of the links between "torture, security, death [...] themes usually imagined as devoid of connection to sexual politics in general and queer politics in particular". Indeed historians of technology have frequently alerted us to 
how missiles, nuclear weaponry and even the systems that control them, reinforce particular masculine and heterosexual norms (Cohn, 1984). The drone itself may be regarded as a manifestation of the way that the United States has flexed its "military phallic muscle", as Cristina Masters has put it (2005:118; see Milliken and Sylvan, 1996 on Vietnam). The possessive delegation to the drone accords with the kinds of discursive unhooking Masters has identified, "from the physical male body and the re-inscription of male subjectivity on/into military technologies" (2005:120). Unsurprisingly but inexcusably, personnel within the US drone program have referred to the Reaper and Predator drones through nicknames such as "Sky Raider" and "Sky Raper" (Corbett, 2015). Of course this follows a wider tendency of the military emasculation of its enemies through sexual violence.

As Gibbon reminds us about the spaces within which drones are sold, the selling of the drone is also marked clearly by sexual desire as well. She identifies the distinction of suited male bodies and the hospitality of low-waged women, serving drinks and canapés, baring cleavage and wearing skirts that are too short. Gibbon's approach, inspired by the Berlin Dadaists, is an explicit rejection of the almost levitating "holy" view of art, a "floating", "head-in-the-clouds" point of view that could barely perceive the violence of war. Of course the Dadaists had levitated a pig-headed military officer in a sculpture suspended from the ceiling in the Heartfield and Schilchter designed Preussischer Erzengel (1920), completed for the Great International Fair in Berlin. Instead Gibbons inhabits and renders the bodies of the drone and the arms trade through its elitist spaces.

How the drone is caught up in other kinds of projects of femininity and masculinity is equally important, but remains largely untold and to a greater extent invisible, despite the realization of warfare with the gender politics of identity, exclusion and sexualized violence. However, it may be that the high public visibility of the drone - its sovereign and "sexual exceptionalism" (Oswin, 2014) - tends to partition away these questions to invisibility, as so often women are silenced from stories of the deployment of drones, or are represented as their unintended victims.

A joint report from the peace activist organizations $\mathrm{Ar}-$ ticle 36 and Reaching Critical Will (2014) on "Sex and Drone Strikes" indicates problems in the very gendered nature of drone targeting. The building up of "pattern of life" signatures around an assumption of a "military-aged male" equalling potential combatant, and innocent "female" being automatically equated as civilian, is also seen in body and casualty counts. For Laura Sjoberg (2014), this tends to cast the "invisibility of men civilians" through a refusal to see them as such. According to the report: assuming all militaryaged men to be "potential" or actual combatants or militants entrenches a tendency to support "violent masculinities". Against this imagination, "a feminized and devalued notion of peace as unattainable, unrealistic, passive and (it might be said) undesirable", is apparently pitched. Thus, whether in the spaces of the drone's making, or the way drones are deployed against targets, the relations between bodies and difference have tended to be obscured beneath the veneers of body-count abstractions and the inaccessible spaces of the drone economy.

\section{Conclusions}

This paper has shown that the mythical, magical and strange figurations and spaces of the levitator do not provide the opportunity for easy comparison with the drone, even if they resonate with the technological fetish with which drones are frequently represented or purveyed. Instead, the paper has shown how levitators reveal different aesthetic and surrealist orders with which we can rethink the drone and its sites of representation, circulation and academic investigation. Such a "making strange" helps us to make the drone visible differently, and begin to reorder, unsettle and reposition the drone within other relations, hierarchies and aesthetic sensibilities.

The paper excavated three different aesthetic registers that levitators might enable us to bring to bear on drones. First, the way we have told stories about levitators does not necessarily emphasize a fidelity to the original event of levity as drone geographers have increasingly sought to achieve, albeit through multiple and messy perspectives that may also speak to the ethos of decentring the drone as "fractional" that this paper has sometimes traced. As we saw, investigators of levitators attempted various forms of spirit photography and ways to unmask fraudulent mediums. However, occasionally holding back from the desire for ever-increasing fidelity to drones, drone strikes and drone networks may help us reevaluate the drone as a more familiar kind of object and set of practices when it is fetishized as myth, and ultimately may more easily subject the drone to comparison and critique.

Second, certain registers of the levitator do not repress the awe, fear or excitement of the drone's fetish or non-human flesh, but amplifies it even further. The theological and mythical fervour of the levitator and the excitable affects and passions that manifest levitation can help us distil various affective relations that also make the drone and drone industries and may serve to upset them. Whether it is the excitement and excess of the military expo or the irony of various techniques to subvert the drone, or the lyrical inhuman agencies Crandall finds in the workings of the drone, our various assumptions about the drone can begin to be unsettled.

Third, the sexual politics of the levitator intersects these affective relations, cutting across them differently. The levitator's exposure and suppression to a longing male gaze can help open up analysis of the drone to perspectives more critical to the gendering and queering of drone geographies, as well as the performance and imitation of violence, sexual or otherwise, which have been so far patently invisible. Gendered and sexualized bodies and identities have been largely 
abstracted from current drone geographies by paying close attention to the abstractions, networks, bureaucracies and legalities - within which these relations are surely composed and reproduced - while overlooking the spaces where drones are sold or consumed.

Let me be clear, however, that I am aware of some of the dangers of these kinds of move, nor do I want to suggest that such an analysis should undo or replace accounts of fidelity characterized through the paper, but rather to sit alongside them. As Benjamin Noys has recently warned, when we interrogate exaggerated "claims of God" tricks, and a wider metaphysical and theological inference of vertical omniscience (2015), the following is true:

The risk of engaging with this theological or metaphysical resonance seriously is that we feed the technological fetishism that can impinge on the thinking of drones. To treat drones as if they were the "travelling eye of God" is to flatter this mundane and brutal surveillance and killing device. We may give a technological object, or technological assemblage, a philosophical dignity it does not deserve (2015:3).

As Noys puts it, it is "only by taking seriously this fetishism that we can sharpen our critical discourse, the better to resist the seductions of drones" (3). In answer, the paper has advanced an argument that tries to take this further in such a way that realizes the profit in understanding the drone as multiple and, thus with the possibility to be seen from alternative points of view. Not content to probe or test the fetishistic and mythological claims of drones, it has sought to hold far more true to their spirit. The possibilities of such a spirit can help us to advance a critique on the drone's own terms in order to subvert its worlds and imagine new ones.

Beyond the drone and the levitator we should realize that the aesthetics, relations and hierarchies discussed in this paper are not so alien to our understandings of other aerial or aeromobile geographies either. Joseph Corn (1983) has already set the birth of aviation in the United States in the context of a messianic Christian belief of spiritual ascension mixed with frontier destiny. The sky was the new frontier of manifest destiny. Flight gave lift to a spiritual and technological imagination sent upwards. A moment of the miraculous, flight became a "holy cause" and the aeroplane a simultaneously technical and spiritual endeavour. Such an imagination of the occupation of the air through levity or ascendance, as we have seen is common, and finds much earlier expression in testimonies and stories of levitating figures, especially in the hagiographies of Catholic saints far before powered flight. These geographies deserve far more scrutiny, just as we may bring them into collision with contemporary geographies of the drone.

To pursue such a line of enquiry may require returning to another ethos, which avoids the sharp demarcations through which the levitator struggled to fit. Instead it may require turning to what Nicola Masciandrio (2013) describes as an "unknowing" of the divisions between disciplinary inquiry, science and rationality, with spirituality, myth and magic, to move towards a more medieval kind of thought where so many levitators were first given form.

Let us levitate the drone.

\section{Data availability}

This paper draws on research initially conducted at the Institute of Advanced Studies, Durham University, where I was a Light Fellow in 2014. The research is primarily textual and archival, and has not produced nor does it rely upon a publicly accessible data set.

Acknowledgements. This paper is drawn from research conducted for a book project on the art, culture and politics of levitation. It was deepened greatly by the workshop "Drone Geographies" held in Neuchatel, Switzerland, organized by Francisco Klauser and Silvana Pedrozo, the thoughtful comments of Kyle Grayson, as well as two referees. The paper also could not have been written without the generous milieu of colleagues and friends, especially Harriet Hawkins. The Institute of Advanced Studies, Durham University, granted me a Light Fellowship in 2013 to begin this work.

Edited by: F. Klauser

Reviewed by: two anonymous referees

\section{References}

Adey, P.: Securing the volume/volumen: Comments on Stuart Elden's Plenary paper "Secure the volume", Polit. Geogr., 34, 5254, 2013.

Adey, P.: Levitation: the science, myth and magic of suspension, Reaktion, London/Chicago University Press, Chicago, forthcoming, 2017.

Adey, P., Whitehead, M., and Williams, A.: From Above: war, verticality and violence, Hurst, Oxford University Press, London, New York, 2013.

Agamben, G.: Homo sacer: Sovereign power and bare life, Stanford University Press, Stanford, CA, 1998.

Agamben, G.: State of exception. University of Chicago Press, Chicago, 2005.

Bachelard, G.: Air and Dreams: An essay on the imagination of movement, Dallas Institute Publications, Dallas Institute of $\mathrm{Hu}-$ manities and Culture, Dallas, TX, 1988.

Berg, N.: Luftmenschen: Zur Geschichte einer Metapher, Gottingen: Vandenhoeck \& Ruprecht GmbH, 2008.

Bergmann, P.: The Riddle of Gravitation, Scribner, New York, 1968.

Bukatman, S.: Matters of gravity: Special effects and supermen in the 20th century, Duke University Press, Durham, NC, 2003.

Calvino, I.: Lightness, in: Six Memos for the New Millennium, Vintage Books, New York, 1988.

Cohn, C.: Slick 'Ems, Glick 'Ems, Christmas Trees, and Cookie Cutters: Nuclear Language and How We Learned to Pat the Bomb, Bulletin of Atomic Scientists, 43, 1984. 
Corbett, E.: On Nicknaming Predators, The Feminist Wire, available at: http://www.thefeministwire.com/2015/06/ on-nicknaming-predators/, 2015.

Corn, J.: The Winged Gospel, Oxford University Press, London, 1983.

Crampton, J. W., Roberts, S. M., and Poorthuis, A.: The new political economy of geographical intelligence, Ann. Assoc. Am. Geogr., 104, 196-214, 2014.

Crandall, J.: Ecologies of a wayward drone, in: From above: war, violence, and verticality, edited by: Adey, P., Whitehead, M., and Williams, A. J., Hurst, Oxford University Press, London, New York, 2014.

Curtis, N.: Sovereignty and Superheroes, Oxford, OUP, 2015.

Della Dora, V.: Gardens of Eden and Ladders to Heaven: holy mountain geographies in Byzantium, in: Mapping Medieval Geographies: Geographical Encounters in the Latin West and Beyond, 300-1600, edited by: Lilley, K., Cambridge University Press, Cambridge, 2014.

Dikeç, M.: Politics is sublime, Environ Plann. D, 30, 262-279, 2012.

Dikeç, M.: Immigrants, banlieues, and dangerous things: ideology as an aesthetic affair, Antipode, 45, 23-42, 2013.

Dittmer, J.: Captain America and the Nationalist Superhero Metaphors, Narratives, and Geopolitics, Philadelphia, Temple University Press, 2012.

Dorrian, M.: Drone Semiosis, Cabinet Magazine, 54, Summer, 4855, 2014.

Dorrian, M. and Pousin, F.: Seeing From Above: The Aerial View in Visual Culture, IB Tauris, London, 2013.

Eliade, M.: Shamanism: Archaic Techniques of Ecstasy, Princeton University Press, Princeton, 1964.

FAA: Busting Myths about the FAA and Unmanned Aircraft Update, available at: http://www.faa.gov/news/updates/?newsId= 76381 (last access: August 2015), 2014.

Fenton, J.: Space, chance, time: walking backwards through the hours on the left and right banks of Paris, Cultural Geogr., 12, 412-428, 2005.

Forsyth, I.: Subversive patterning: The surficial qualities of camouflage, Environ. Plann. A, 45, 1037-1052, 2013.

Forsyth, I.: More-than-human warfare, Soc. Cult. Geogr., 1-5, 2016.

Gibbon, J.: Hiding in the Light: drawings of arms fairs, in: Masquerades of War, edited by: Sylvester, C., Routledge, London, 190-196, 2015.

Graham, S. and Hewitt, L.: Getting off the ground On the politics of urban verticality, Prog. Hum. Geog., 37, 72-92, 2013.

Gratton, P.: State of Sovereignty, The: Lessons from the Political Fictions of Modernity, New York, SUNY Press, 2012.

Gregory, D.: From a view to a kill drones and late modern war, Theor. Cult. Soc., 28, 188-215, 2011.

Gregory, D.: Angry Eyes (2), geographical imaginations, available at: http://geographicalimaginations.com/2015/10/07/ angry-eyes-2/, last access: October 2015.

Gonzalez, J.: Remedios Varo, in: Remedios Varo: Catalogue Raisonne (fourth edition), edited by: Ovalle, R., Ediciones Era, 2008.

Hawkins, H.: Geography and art. An expanding field Site, the body and practice, Prog. Hum. Geogr., 37, 52-71, 2013.
Hawkins, H. and Straughn, E. (Eds.): Aesthetic Geographies, Aldershot, Ashgate, 2015.

Hiller, S.: Levitations: Homage to Yves Klein. Auras: Homage to Marcel Duchamp, Institute of Contemporary Art, London, 2009.

Ingram, A.: Rethinking art and geopolitics through aesthetics: artist responses to the Iraq war, T. I. Brit. Geogr., 41, 1-13, 2016.

Jablonowski, M.: Drone It Yourself! On the Decentring of "Drone Stories", Culture Machine, 16, 1-15, 2015.

Jackman, A. H.: Rhetorics of possibility and inevitability in commercial drone tradescapes, Geogr. Helv., 71, 1-6, doi:10.5194/gh-71-1-2016, 2016.

Kantorowicz, E.: The King's Two Bodies: A Study of Medieval Political-Theology, Princeton University Press, Princeton, NJ, 1957.

Kindervater, K. H.: Lethal Surveillance: Drones and the GeoHistory of Modern War, Doctoral dissertation, University of Minnesota, 2015.

Law, J.: Aircraft stories: Decentering the object in technoscience, Duke University Press, Durham, NC, 2002.

Machold, R.: Mobility and the model: policy mobility and the becoming of Israeli homeland security dominance, Environ. Plann. A, 47, 816-832, 2015.

Marshall, D. J.: All the beautiful things: Trauma, aesthetics and the politics of Palestinian childhood, Space and Polity, 17, 53-73, 2013.

Masciandrio, N.: Grave Levitation, in: Loveee Journal, edited by: Rizzo, C. and Amara, L., 102-111, 2013.

Masters, C.: Bodies of technology: Cyborg soldiers and militarized masculinities, International Feminist Journal of Politics, 7, 112132, 2005.

Mazzoni, C.: Saint hysteria: neurosis, mysticism, and gender in European culture, Cornell University Press, New York, 1996.

McCormack, D.: The Allure of the Atmospheric: Envelopment, Sensing, Media, Duke University Press, Durham, NC, in press, 2017.

Milliken, J. and Sylvan, D.: Soft bodies, hard targets and chic theories: US bombing policy in Indochina, Millennium: Journal of International Studies, 25, 321-359, 1996.

Morshed, A.: The Aesthetics of Ascension in Norman Bel Geddes's Futurama, The Journal of the Society of Architectural Historians, 74-99, 2004.

Nancy, J. L.: The creation of the world, or, globalization, Suny Press, New York, 2007.

Neocleous, M.: Air power as police power, Environ. Plann. D, 31, 578-593, 2013.

Noys, B.: Drone Metaphysics, Culture Machine, 16, 1-22, 2015.

Oswin, N.: Queer theory, in: The Handbook of Mobilities, edited by: Adey, P., Bissell, D., Hannam, K., Merriman, P., and Sheller, M., Routledge, London, 85-93, 2014.

Pinder, D.: Visions of the city: utopianism, power and politics in twentieth century urbanism, Routledge, London, 2013.

Puar, J. K.: Terrorist Assemblages: Homonationalism in Queer Times, Durham, NC, Duke University Press, 2007.

Ranciere, J.: The Politics of Aesthetics: The Distribution of the Sensible, Bloomsbury, London, 2006.

Rothstein, A.: Drone. Bloomsbury Publishing, London, 2015.

Satia, P.: Drones: A History from the British Middle East, Humanity, 5, 1-31, 2014. 
Scammell, M.: Koestler: the literary and political odyssey of a twentieth-century skeptic, Faber and Faber, London, 2011.

Shaw, I.: Drone Theory?, Antipode, available at: https: //radicalantipode.files.wordpress.com/2015/06/book-review_ shaw-on-rothstein-and-chamayou.pdf, last access: August 2015.

Shaw, I.: Scorched Atmospheres: The Violent Geographies of the Vietnam War and the Rise of Drone Warfare, Ann. Assoc. Am. Geogr., 106, 688-704, 2016.

Shaw, I. and Akhter, M.: The unbearable humanness of drone warfare in FATA, Pakistan, Antipode, 44, 1490-1509, 2012.

Slagter, P.: DARPA Nano Hummingbirds and Poppies, available at: http://www.crossmackenzie.com/blast-off-april-2015/, 2015.

Sjoberg, L.: Gender, War and Conflict, Wiley, Oxford, 2014.

Stites, R.: Revolutionary dreams: Utopian vision and experimental life in the Russian revolution, Oxford, OUP, 1989.

Sweeney-Risko, J.: Elsa Schiaparelli, The New Woman, and Surrealist Politics, Interdisciplinary Literary Studies, 17, 309-329, 2015.
Thornton, P.: The meaning of light: seeing and being on the battlefield, Cult. Geogr., 2015.

Wall, T. and Monahan, T.: Surveillance and violence from afar: The politics of drones and liminal security-scapes, Theor. Criminol., 15, 239-254, 2011.

Warma, S.: Ecstasy and Vision: Two Concepts Connected with Bernini's Teresa, The Art Bulletin, 66, 508-511, 1984.

Wolff, J.: On the road again: metaphors of travel in cultural criticism, Cult. Stud., 7, 224-239, 1993.

Wylie, J.: An essay on ascending Glastonbury Tor, Geoforum, 33, 441-454, 2002.

Vidal, F.: Miracles, Science, and Testimony in Post-Tridentine Saint-Making, Sci. Context, 20, 481-508, 2007. 